\title{
Multidimensionality of Modification in an Isopod-Acanthocephalan System
}

\author{
Tracey Park and Timothy C. Sparkes* \\ Department of Biological Sciences, DePaul University, Chicago, IL, United States
}

The acanthocephalan parasite Acanthocephalus dirus infects the freshwater isopod Caecidotea intermedius as an intermediate host before completing its life cycle in a fish. Transmission to the definitive host occurs after the parasite has reached the cystacanth stage and development into this stage is associated with changes in several behavioral and physiological traits of the host. Despite the numerous examples of trait modification in this system, little is known about the multidimensional nature of this modification. Here, we examined the relationships between cystacanth infection, and expression of multiple traits (body color, refuge use, activity, and body size) of both male and female C. intermedius. The pattern of multidimensional modification was determined for males and females and then measures of behavioral plasticity, individual consistency, and trait correlations were obtained for the modified traits. The results revealed that the overall pattern of host modification differed between males and females. Infected males and females showed similar decreases in body color but differed in changes to the other

\section{OPEN ACCESS}

Edited by:

Marta Isabel Sánchez, Consejo Superior de Investigaciones Científicas (CSIC), Spain

Reviewed by:

Sandra Breum Andersen, University of Oxford, United Kingdom Nina Hafer

Max Planck Institute for Evolutionary Biology (MPG), Germany

*Correspondence: Timothy C. Sparkes tsparkes@depaul.edu

Specialty section:

This article was submitted to Behavioral and Evolutionary Ecology, a section of the journal

Frontiers in Ecology and Evolution

Received: 14 June 2017

Accepted: 17 August 2017 Published: 01 September 2017

Citation:

Park T and Sparkes TC (2017) Multidimensionality of Modification in an Isopod-Acanthocephalan System.

Front. Ecol. Evol. 5:103.

doi: 10.3389/fevo.2017.00103 traits. Infected females were larger and less active than uninfected females, whereas infected males spent less time in refuge than uninfected males. A comparison between two situations revealed that refuge use exhibited high levels of plasticity and activity exhibited high levels of consistency and that these patterns differed based on both host sex and infection status. Analysis of the relationships among modified traits showed that traits appeared to be modified independently of each other and that correlations between traits that existed in one situation were absent in another. We suggest that the pattern of multidimensional modification is sex-specific and that the traits are modified independently. We also show that the patterns of multidimensional modification were not associated with variation in either parasite intensity of parasite size indicting that competitive interactions among parasites did not appear to act as a constraint on host modification.

Keywords: parasitic manipulation, trophic transmission, Acanthocephalus dirus, Caecidotea intermedius, body color, body size, activity, refuge use

\section{INTRODUCTION}

The importance of parasites to host behavior has become evident in recent years with numerous studies documenting parasite-related trait modification in parasites that are trophically transmitted (e.g., Moore, 2002; Lefèvre et al., 2009; Poulin, 2010; Hughes et al., 2012; Lafferty and Shaw, 2013). Although several examples of changes to individual traits have been documented, less is known about multi-trait modification (Cézilly and Perrot-Minnot, 2005, 2010; Thomas et al., 2005, 2010, 2012; Lefèvre et al., 2009; Poulin, 2010; Adamo, 2012, 2013; Cézilly et al., 2013; Perrot-Minnot and Cézilly, 2013). Studying multidimensional modification is beneficial because it allows for an 
examination of the relationships among modified traits, which can provide insights into proximate mechanisms underlying modification (Cézilly and Perrot-Minnot, 2005; Benesh et al., 2008; Perrot-Minnot et al., 2014), and because it can help to determine if the relationships among traits may be the targets of manipulation (Poulin, 2010). In addition, when multidimensional modification is examined across different situations, the potential importance of behavioral plasticity (differences in behavior between situations), and individual consistency (consistent among-individual variation in behavior) to trait modification can be determined (e.g., Barber and Dingemanse, 2010; Coats et al., 2010; Hammond-Tooke et al., 2012; Cézilly et al., 2013; Poulin, 2013; Seaman and Briffa, 2015). We examined the simultaneous modification of multiple traits in male and female hosts across two situations in a host in which multiple behavioral and physiological traits have been shown to be modified individually.

Another aspect of multidimensional modification that requires more analysis concerns the impacts of competitive interactions among parasites that share a host. Numerous studies have shown that host sharing can impact parasite development, growth, body size, and energy content, and that each of these factors has the potential to influence trait modification (Read and Phifer, 1959; Roberts, 2000; Dezfuli et al., 2001; Sparkes et al., 2004, 2006; Benesh and Valtonen, 2007a; Franceschi et al., 2008, 2010; Benesh et al., 2009a; Dianne et al., 2010, 2012; Caddigan et al., 2014, 2017). If competitive interactions among parasites influence the patterns of development, growth, and energy allocation, and if manipulation is costly, then parasites may benefit by adopting strategies that balance the conflicting demands associated with their own growth, and development with those that are associated with host manipulation (e.g., Poulin, 1994a; Parker et al., 2003; Thomas et al., 2005, 2011; Michaud et al., 2006; Ball et al., 2008; Franceschi et al., 2010; Maure et al., 2013). Consistent with this type of mechanism, infection of an aquatic isopod by an acanthocephalan parasite is associated with decreases in both parasite energy content, and modification of host behavior (mating) at higher intensities of infection (Caddigan et al., 2014, 2017). Thus, by examining the relationship between parasite intensity and multidimensional modification, insights can be gained into both manipulation strategies, and constraints that may be imposed on these strategies by competition.

Acanthocephalans are trophically transmitted parasites that infect arthropods as intermediate hosts and vertebrates as definitive hosts (Kennedy, 2006). Modification of host traits is relatively common in these parasites and there is evidence that these changes increase predation by definitive hosts (e.g., Camp and Huizinga, 1979; Brattey, 1983; Moore, 1983; Lagrue et al., 2007; but see Kaldonski et al., 2009; Perrot-Minnot et al., 2012). Numerous major insights have been gained in the area of host modification by researchers working on the relationship between acanthocephalans and amphipod hosts (Gammarus spp., e.g., Cézilly et al., 2013). Running parallel to these studies, several decades of research on acanthocephalan-related modification in isopod hosts have identified similar patterns to those identified in amphipod hosts.
Representative publications on trait modification in isopods from the early 1970s until 2017 are summarized in Table 1. These studies document that modification occurs in at least nine isopod-acanthocephalan relationships from eight countries (Brazil, England, Finland, Poland, Italy, Japan, Scotland, United States) representing four continents (Asia, Europe, North America, South America). The numerous modified traits include those that are expected to influence conspicuousness (e.g., body color, body size, activity, refuge use), those that may influence patterns of energy allocation (e.g., reproduction, feeding behavior, energy content), and those that are associated with proximate mechanisms that may underlie trait modification (e.g., serotonin, dopamine). Several general patterns have emerged from these studies. First, body color is often modified but this modification can occur in different ways. In European systems, acanthocephalan infection is associated with increased deposition of melanin, and an overall "darkening" of the body color. In contrast in American systems, acanthocephalan infection is often associated with a "lightening" of the body color due to a decrease in pigment deposition. Both types of color changes are expected to increase contrast with the natural background, and hence increase conspicuousness to definitive hosts. Second, modification can occur in a sex-specific manner. For example, suppression of mating in infected females is typically associated with an atrophy of the reproductive organs which appears to be irreversible. In contrast, mating suppression in males is behavioral, and the effect can be reversed. Third, almost all of the studies have been conducted on individual traits examined at the population-level (i.e., changes in average trait value), which emphasizes the need for studies that examine trait modification from a multidimensional perspective (see Benesh et al., 2008 for the exception).

The freshwater isopod Caecidotea intermedius is a host of the acanthocephalan parasite Acanthocephalus dirus and undergoes modification of behavioral and physiological traits (Table 1). Generally, infected $C$. intermedius have a more conspicuous body color, and are more likely to be located in the open than uninfected isopods, which is associated with an increased rate of predation on infected individuals (Camp and Huizinga, 1979). This behavioral shift does not appear to be due to energy constraints because feeding behavior is not increased in the open (Hechtel et al., 1993; Korkofigas, 2007) and because infected individuals contain more stored energy (glycogen and lipid) than uninfected individuals (Korkofigas et al., 2016). There is also evidence of sex-specific effects of modification in this hostparasite relationship. Infected males and females are less likely to engage in mating behavior than uninfected males and females (Sparkes et al., 2006). In males, this decrease is due to a reduction in the behavioral response to females during an encounter and is reversible (Bierbower and Sparkes, 2007). In contrast, mating suppression in females is associated with atrophy of the reproductive organs and appears to be irreversible (Oetinger, 1987; Sparkes et al., 2006).

We examined the relationships among $A$. dirus infection and trait modification for four traits: refuge use, activity, body color, body size. All four of these traits have the potential to influence transmission by increasing conspicuousness of infected 
TABLE 1 | Examples of acanthocephalan-related modification of behavioral and physiological traits of isopod hosts.

\begin{tabular}{|c|c|c|c|c|}
\hline Species & $\begin{array}{l}\text { Isopod } \\
\text { host }\end{array}$ & $\begin{array}{l}\text { Location, } \\
\text { habitat }\end{array}$ & Trait modification & References \\
\hline \multirow[t]{3}{*}{$\begin{array}{l}\text { Acanthocephalus } \\
\text { dirus }\end{array}$} & $\begin{array}{l}\text { Caecidotea } \\
\text { intermedius }\end{array}$ & $\begin{array}{l}\text { N. America, } \\
\text { Aquatic }\end{array}$ & $\begin{array}{l}\downarrow C, \downarrow R, \downarrow M, \downarrow F, \downarrow N \\
\uparrow A, \uparrow E, \uparrow S^{F} \uparrow P\end{array}$ & $1-16$ \\
\hline & $\begin{array}{l}\text { Lirceus } \\
\text { lineatus }\end{array}$ & $\begin{array}{l}\text { N. America, } \\
\text { Aquatic }\end{array}$ & $\begin{array}{l}\downarrow C, \downarrow R, \downarrow M \\
\uparrow A\end{array}$ & $\begin{array}{c}2,4,17,18 \\
19\end{array}$ \\
\hline & $\begin{array}{l}\text { Lirceus } \\
\text { garmani }\end{array}$ & $\begin{array}{l}\text { N. America, } \\
\text { Aquatic }\end{array}$ & $\downarrow C$ & 2,4 \\
\hline $\begin{array}{l}\text { Acanthocephalus } \\
\text { tahlequahensis }\end{array}$ & $\begin{array}{l}\text { Caecidotea } \\
\text { communis }\end{array}$ & $\begin{array}{l}\text { N. America, } \\
\text { Aquatic }\end{array}$ & $\downarrow F, \downarrow E, \downarrow M^{F}$ & 20,21 \\
\hline $\begin{array}{l}\text { Acanthocephalus } \\
\text { lucii }\end{array}$ & $\begin{array}{l}\text { Asellus } \\
\text { aquaticus }\end{array}$ & $\begin{array}{l}\text { Europe, } \\
\text { Aquatic }\end{array}$ & $\begin{array}{l}\downarrow R, \downarrow M^{F} \\
\uparrow C, \uparrow A, \uparrow S\end{array}$ & $22-31$ \\
\hline $\begin{array}{l}\text { Acanthocephalus } \\
\text { anguillae }\end{array}$ & $\begin{array}{l}\text { Asellus } \\
\text { aquaticus }\end{array}$ & $\begin{array}{l}\text { Europe, } \\
\text { Aquatic }\end{array}$ & $\begin{array}{l}\downarrow M \\
\uparrow C, \uparrow A, \uparrow P\end{array}$ & $23,24,32$ \\
\hline $\begin{array}{l}\text { Acanthocephalus } \\
\text { sp. }\end{array}$ & $\begin{array}{l}\text { Asellus } \\
\text { hilgendorfi }\end{array}$ & $\begin{array}{l}\text { Asia, } \\
\text { Aquatic }\end{array}$ & $\begin{array}{l}\downarrow M^{F} \\
\uparrow S^{F}\end{array}$ & 33 \\
\hline $\begin{array}{l}\text { Centrorhynchus } \\
\text { sp. }\end{array}$ & $\begin{array}{l}\text { Atlantoscia } \\
\text { floridana }\end{array}$ & $\begin{array}{l}\text { S. America, } \\
\text { Terrestrial }\end{array}$ & $\downarrow C$ & 34 \\
\hline $\begin{array}{l}\text { Plagiorhynchus } \\
\text { cylindraceus }\end{array}$ & $\begin{array}{l}\text { Armadillidium } \\
\text { vulgare }\end{array}$ & $\begin{array}{l}\text { N. America, } \\
\text { Terrestrial }\end{array}$ & $\begin{array}{l}\downarrow R, \downarrow M \\
\uparrow A^{F}\end{array}$ & 35 \\
\hline
\end{tabular}

S, size (body length, body area, body mass, propodus length, dactylus length, pleotelson width); $C$, color (body pigmentation); $M$, mating activity (mating response, mate guarding, egg production); $R$, refuge use; $A$, activity; $F$, feeding behavior; $E$, energy content (glycogen, lipid, total energy); N, neurochemical levels (dopamine, serotonin); P, predator attraction. ${ }^{F}$ female only (for cases where members of both sexes were examined).

${ }^{1}$ Seidenberg (1973), ${ }^{2}$ Camp and Huizinga (1979), ${ }^{3}$ Camp and Huizinga (1980), ${ }^{4}$ Oetinger and Nickol (1981), ${ }^{5}$ Oetinger and Nickol (1982a), ${ }^{6}$ Oetinger and Nickol (1982b), ${ }^{7}$ Oetinger (1987), ${ }^{8}$ Hechtel et al. (1993), ${ }^{9}$ Sparkes et al. (2004), ${ }^{10}$ Sparkes et al. (2006), ${ }^{11}$ Bierbower and Sparkes (2007), ${ }^{12}$ Korkofigas (2007), ${ }^{13}$ Caddigan et al. (2014), ${ }^{14}$ Kopp et al., 2016, ${ }^{15}$ Korkofigas et al. (2016), ${ }^{16}$ Caddigan et al. (2017), ${ }^{17}$ Muzzall and Rabalais (1975a), ${ }^{18}$ Muzzall and Rabalais (1975b), ${ }^{19}$ Muzzall and Rabalais (1975c), ${ }^{20}$ Hernandez and Sukhdeo (2008), ${ }^{21}$ Lettini and Sukhdeo (2010), ${ }^{22}$ Brattey (1983), ${ }^{23}$ Pilecka-Rapacz (1986), ${ }^{24}$ Lyndon (1996), ${ }^{25}$ Benesh and Valtonen (2007b), ${ }^{26}$ Hasu et al. (2007), ${ }^{27}$ Benesh et al. (2008), ${ }^{28}$ Seppälä et al. (2008), ${ }^{29}$ Benesh et al. (2009a), ${ }^{30}$ Benesh et al. (2009b), ${ }^{31}$ Hasu (2013), ${ }^{32}$ Dezfuli et al. (1994), ${ }^{33}$ Kakizaki et al. (2003), ${ }^{34}$ Amato et al. (2003), ${ }^{35}$ Moore (1983).

isopods to predatory definitive hosts (Holomuzki and Short, 1988, 1990; Huang and Sih, 1990; Sparkes, 1996; Hargeby et al., 2004, 2005). Using these approaches, we addressed the following specific questions. (1) Does simultaneous multidimensional modification occur and is the pattern of modification sexspecific? Given that there is sexual size dimorphism in $C$. intermedius, parasites are expected to adopt different strategies of host exploitation in male and female hosts to maximize their own fitness payoffs. (2) Do phenotypic correlations occur among modified traits? Proximate mechanisms that are shared among modified traits are expected to modify multiple traits in a correlated manner. (3) Is there plasticity and consistency in behavior modification between situations? Changes in trait expression between situations provides insights into the importance of local conditions to behavior modification and determines whether parasite infection may be shaping animal personalities. (4) Is the pattern of multidimensional modification associated with variation in parasite characteristics? A negative relationship between host modification and infection intensity could indicate that competition among parasites acts as a constraint on the strategy of host manipulation adopted by the parasites.

\section{MATERIALS AND METHODS}

Infected and uninfected $C$. intermedius were collected from Buffalo Creek located in Lake County, Illinois, USA $\left(42^{\circ} 11^{\prime} 9^{\prime \prime} \mathrm{N}\right.$, $\left.88^{\circ} 3^{\prime} 27^{\prime \prime} \mathrm{W}\right)$. In this population, development of $A$. dirus is relatively synchronous with infection of $C$. intermedius occurring during the late-spring and summer when eggs are consumed with detritus (Sparkes et al., 2004). Inside the isopod, the parasite develops from the larval stage (acanthor) to the mature stage (cystacanth) in $\sim 2-3$ months (Sparkes et al., 2004), which results in the $A$. dirus population being dominated by cystacanths during late-winter and spring. After this time, all surviving isopods senesce, which removes any remaining $A$. dirus cystacanths from the population (Wahl and Sparkes, 2012). Definitive hosts in this site include creek chub (Semotilius atromaculatus), green sunfish (Lepomis cyanellus), and bluegill sunfish (Lepomis macrochirus). During the spring ( $\sim 9-11$ months post-infection), several traits are modified in infected isopods (Table 1).

To determine if $A$. dirus infection was associated with multidimensional modification, we examined variation in the expression of four traits (refuge use, activity, body color, body size) in males, and females. Refuge use and activity were measured both at the field site and in the laboratory (on the following day). Measures of body color and body size were obtained for each individual after the measures of behavior had been collected. This was not expected to be a concern because body color has been shown to be consistent over longer timeperiods than were examined here (Hargeby et al., 2004) and because changes in body size require a molt, which would have been identified it if had occurred. The plasticity and consistency of behavior was assessed using the measures of refuge use and activity obtained at the field site and in the laboratory.

Isopods were collected from Buffalo Creek on 5 days during April and May, 2015 (April 11, 18, 26, May 3, 10) between 10:00 and 10:30 in the morning. On each day, the isopods were captured by both running a net through submerged vegetation and by placing a net downstream while lifting rocks from the substrate. Natural variation in body color was used to distinguish between infected isopods (white or yellow colored) and uninfected isopods (brown colored). Infection status was later confirmed using dissections, and isopods were re-categorized prior to analysis. Dimorphism in size and shape between the sexes was used to differentiate between males and females (Keogh and Sparkes, 2003).

The animals used in the study did not require approval from the Institutional Animal Care and Use Committee (IACUC) because they are invertebrates.

\section{Refuge Use and Activity}

To determine the relationships between refuge use and $A$. dirus infection, we used a behavioral assay with individuals from the four focal groups (uninfected male, infected male, uninfected female, infected female). Isopods were collected from the stream and assigned to holding arenas (round plastic containers, $8 \mathrm{~cm}$ 
diameter, $5 \mathrm{~cm}$ height, partially-filled with stream water) where they acclimated for 5 min prior to trial $(n=48$ per day, $n=$ 240 total). Each isopod was then transferred to an experimental arena (rectangular plastic container, $26 \times 15 \times 12 \mathrm{~cm}$, partiallyfilled with stream water), which sat inside a larger tray located on the stream-bank $(89 \times 42 \times 16 \mathrm{~cm})$. Each tray contained four experimental arenas and each arena housed one member of each of the four groups. One isopod from each group was assigned to one of the holding arenas in each tray using a random number table (Lentner and Bishop, 1986). Experimental arenas also contained three ellipsoid-shaped rocks purchased from a pet supplier. The rocks were pre-sorted into three categories (small $\approx 28 \times 19 \times 9 \mathrm{~mm}$, medium $\approx 31 \times 22 \times 11 \mathrm{~mm}$, large $\approx 35$ $\times 26 \times 12 \mathrm{~mm}$ ) and placed in the arena in a line. Each rock was raised from the base of the arena by three small pebbles that were attached to the underside of the rocks using aquarium glue. Observations of refuge use were made every $5 \mathrm{~min}$ for a total of $30 \mathrm{~min}$, yielding six data points per trial $(5,10,15,20,25$, and 30 $\mathrm{min})$. During each observation, we recorded whether the isopod was exposed (on top of the rock, on the side of the rock, or in the open) or in refuge (under the rock). For the analysis of refuge use for each isopod, the percentage of time spent in refuge was calculated using the six values obtained per trial.

Following completion of the behavioral trials, each isopod was transferred to a holding arena $(8 \mathrm{~cm}$ diameter, $5 \mathrm{~cm}$ height, partially-filled with stream water) prior to use in the activity trials. To determine if the activity of isopods was associated with $A$. dirus infection, grids $(2.5 \times 2.5 \mathrm{~cm})$ were placed beneath activity arenas (round, transparent, plastic containers, $18 \mathrm{~cm}$ diameter, 8 $\mathrm{cm}$ height partially-filled with stream water). Isopods were then transferred to the activity arenas, and observed individually for $5 \mathrm{~min}$. During each observation, the total number of grid lines crossed was recorded using a hand tally-counter. These values were then converted to distance measures $(\mathrm{cm})$ by multiplying the number of gridlines crossed by 2.5 .

On completion of the activity trials, each isopod was placed individually into a vial $(50 \mathrm{ml})$ filled with stream water and transported to the laboratory on the DePaul campus. In the laboratory, isopods were transferred to individual holding arenas ( $8 \mathrm{~cm}$ diameter, $5 \mathrm{~cm}$ height, partially-filled with stream water) and left undisturbed overnight. On the following day, refuge use and activity trials were run during the same time-period, and with the same procedures that were used at the field site. Each isopod was then frozen $\left(-20^{\circ} \mathrm{C}\right)$ in an Eppendorf tube to maintain the body color in its field state (Hargeby et al., 2004; Benesh et al., 2008). The sex of each isopod was confirmed with a dissecting microscope using anatomical characters (presence of oöstegites or a brood pouch in females, presence of enlarged gnathopods and hemi-peni in males).

\section{Body Color and Body Size}

Body color measures were obtained using image analysis software (ImageJ: https://imagej.nih.gov/ij/) on digital images captured using a Cannon PowerShot SX40 HS digital camera. Isopods were photographed individually from a standardized orientation and distance $(13 \mathrm{~cm})$. For each image that was captured, the isopod was defrosted and laid flat in a tray and photographs were taken of the dorsal surface. This surface was used because it represents the region of the isopod that would most likely be observed by predators (Benesh et al., 2008). Each photograph also included a measurement scale $(10 \mathrm{~mm})$ and a color reference (white, several yellows, and several browns) that was based on region 5.5YR-2.5Y from a color strip available in Lenneberg and Roberts (1956). The color reference included the range of colors typically observed in infected and uninfected isopods (white, yellow, brown).

Measurements of body size and body color were obtained using the digital images captured of each isopod. Body size was calculated as the dorsal surface area $\left(\mathrm{mm}^{2}\right)$. To measure body color, we created a color index, which included two color components (color type, proportion of body with color). To measure the type of color, we created a color scoring system that ranged from 0 to 8 . A score of zero was associated with no color (white appearance) and would represent an isopod that lacked color pigment. Scores between 1 and 8 included isopods than ranged in color from light yellow (score $=1$ ) to dark brown (score $=8$ ). These values were then divided by 8 to yield standardized values that ranged from 0 to 1 . The proportion of the body that contained color pigment (proportion color) was measured for the entire dorsal surface. To obtain this measure, we first recorded the surface area of the body and then recorded the areas of all regions of the body that contained brown pigment. The intestines, which are dark colored and visible through the exoskeleton, were excluded (Hargeby et al., 2004). The proportion of color was then calculated as the area containing color pigment divided by the total area of the body. To obtain an overall measure of color (color index), we calculated an average of the two color scores. This value was then used because it accounts for variation in both color measures. We also used principal component analysis (PCA) to obtain principal component values to represent color. The PC analysis was run in parallel with those for color index. The color index was preferred for data visualization because the values obtained are more intuitive than principal component values.

\section{Parasite Characteristics}

Isopods were dissected to obtain measures of parasite characteristics (intensity, size) that may be relevant to patterns of host modification. For each $A$. dirus recovered, we recorded developmental stage (acanthella cystacanth), length, and width. Length and width were used to calculate parasite volume $[((\pi$ $\times$ length $\times$ width $\left.^{2}\right) / 6$ ), Dezfuli et al., 2001]. An individual was categorized as a cystacanth if it had undergone invagination of the proboscis and if there was complete development of both the reproductive organs and the spines of the proboscis (Hasu et al., 2007). Parasite sex was assigned based on the presence of testes or ovarian balls. Parasite intensity was recorded as the number of A. dirus present per infected isopod (Bush et al., 1997).

\section{Data Analysis}

Analysis was performed using Systat (version 13). The relationships between parasite infection, body color, behavior (refuge use, activity), and body size were analyzed separately for males and females. The values used were generally not normally 
distributed (Shapiro-Wilk test) despite transformations; therefore, non-parametric tests were used (Mann-Whitney $U$-tests). To determine the level of consistency and plasticity of the behaviors measured (refuge use, activity), we used the values obtained both at the field site and in the laboratory for the same individuals. Plasticity was assessed using Wilcoxon tests (paired by individual organisms) with two-sided probabilities calculated from an approximate normal variate. Consistency was assessed using Kendall's correlation of concordance (Briffa et al., 2008). Spearman rank-order correlations were used to analyze the relationships between trait-pairs. To determine the potential impact of parasite characteristics (parasite intensity, parasite size) on each of the focal traits, we used Spearman rank-order correlation analysis.

\section{RESULTS}

Body color was used at the field site to tentatively assign infection status (infected and uninfected), and body size was used to assign isopod sex. On completion of the dissections, the sex and infection status of each isopod was confirmed. Sex was assigned correctly for all of the isopods, and infection status was assigned correctly for $89 \%$ of the isopods. In all cases, isopods that were categorized incorrectly at the field site appeared to be uninfected (i.e., dark brown coloration) but contained one or more A. dirus parasites. Following the recategorization of isopods, the sample sizes that were available for analysis were as follows: maleuninfected, $n=40$, male-infected $n=49$, female-uninfected, $n=42$, female-infected, $n=48$ (total $=179$ ). These numbers represent a relatively significant reduction in sample size based on the number of organisms that were originally collected for the study $\left(n_{\text {original }}=240, n_{\text {final }}=179\right.$, reduction $\left.=25 \%\right)$. This reduction was due to several factors (e.g., mortality at the field site and in laboratory, escape in the laboratory), and will need to be accounted for more effectively in future studies.

For the infected isopods that were included in the analysis, mean parasite intensity was $1.4(S D=0.61$, range $=1-4$, $n_{\text {A.dirus }}=131$ ). The A. dirus that were present were typically in the cystacanth stage (93\%), and the female to male sex ratio (F:M) was $\sim 1: 1(53 \mathrm{~F}: 47 \mathrm{M})$. These values were generally similar between male and female hosts (male hosts: mean intensity = 1.4, cystacanths $=93 \%$, sex ratio $=53 \mathrm{~F}: 47 \mathrm{M}$; female hosts: mean intensity $=1.3$, cystacanths $=93 \%$, sex ratio $=53 \mathrm{~F}: 47 \mathrm{M})$. There was no detectable difference in either parasite intensity or parasite size (mean volume) between male hosts and female hosts (intensity: $U=1,037, d f=48,49, P>0.05$, size: $U=1,020, d f=$ 48,49, $P>0.05)$.

\section{Multidimensional Modification}

The relationships between infection status and modification of each of the focal traits are summarized in Table 2. The effect of infection on body size differed between the sexes (males: $U=$ 1,174, $d f=49,40, P>0.05$; females: $U=1618, d f=48,42, P<$ $0.001)$. Infected and uninfected males did not differ in body size. In contrast, infected females were larger than uninfected females (Figure 1).
The two measures of color that were used to create the color index (color type, proportion color) were highly correlated $\left(r_{s}=0.87\right)$. Figures 2, 3 illustrate the variation in color index present for infected and uninfected individuals. Body color differed between infected and uninfected isopods for both sexes (males: $U=218, d f=49,40, P<0.001$; females: $U=$ 232, $d f=48,42, P<0.001)$. Infected isopods were generally light in color (color type $=0-2$ ), with most of the dorsal surface lacking pigmentation (proportion color $=0.01-0.06$ ). In contrast, uninfected isopods were generally dark brown in color (color type $=6-8$ ), with most of the body containing pigmentation (proportion color $=0.8-1.0$ ). Principal component (PC) values obtained for the correlated measures of color explained $91 \%$ of the variation in the components. The same patterns as those described above were found using the PC-values

TABLE 2 | Multidimensional modification in the C. intermedius - A. dirus relationship.

\begin{tabular}{|c|c|c|c|c|}
\hline $\begin{array}{l}\text { Host } \\
\text { sex }\end{array}$ & Trait & Infected & Uninfected & $p$-value \\
\hline \multirow[t]{4}{*}{ Male } & Body size $\left(\mathrm{mm}^{2}\right)$ & $43.9(26.8,56.2)$ & $38.3(26.6,46.3)$ & ns \\
\hline & Refuge use (\%) & $33(0,87)$ & $67(17,100)$ & * \\
\hline & Activity (cm) & $88(10,188)$ & $115(28,198)$ & ns \\
\hline & Color index (0-1) & $0.35(0.24,0.58)$ & $0.94(0.88,0.94)$ & 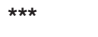 \\
\hline \multirow[t]{4}{*}{ Female } & Body size $\left(\mathrm{mm}^{2}\right)$ & $30.7(23.8,35.0)$ & $19.8(16.6,26.1)$ & $* * *$ \\
\hline & Refuge use (\%) & $50(17,87)$ & $67(33,96)$ & ns \\
\hline & Activity (cm) & $68(12,158)$ & $158(70,208)$ & * \\
\hline & Color index (0-1) & $0.30(0.25,0.46)$ & $0.94(0.88,0.98)$ & $* \star \star$ \\
\hline
\end{tabular}

Shown are median values with upper and lower quartiles in parentheses. *Indicates $P<0.05,{ }^{* * *}$ Indicates $P<0.001$. Modified traits are shown in bold. Analysis of principal component values for color also revealed significant differences between uninfected and infected individuals for both sexes (male: $P<0.001$; female: $P<0.001$ ).

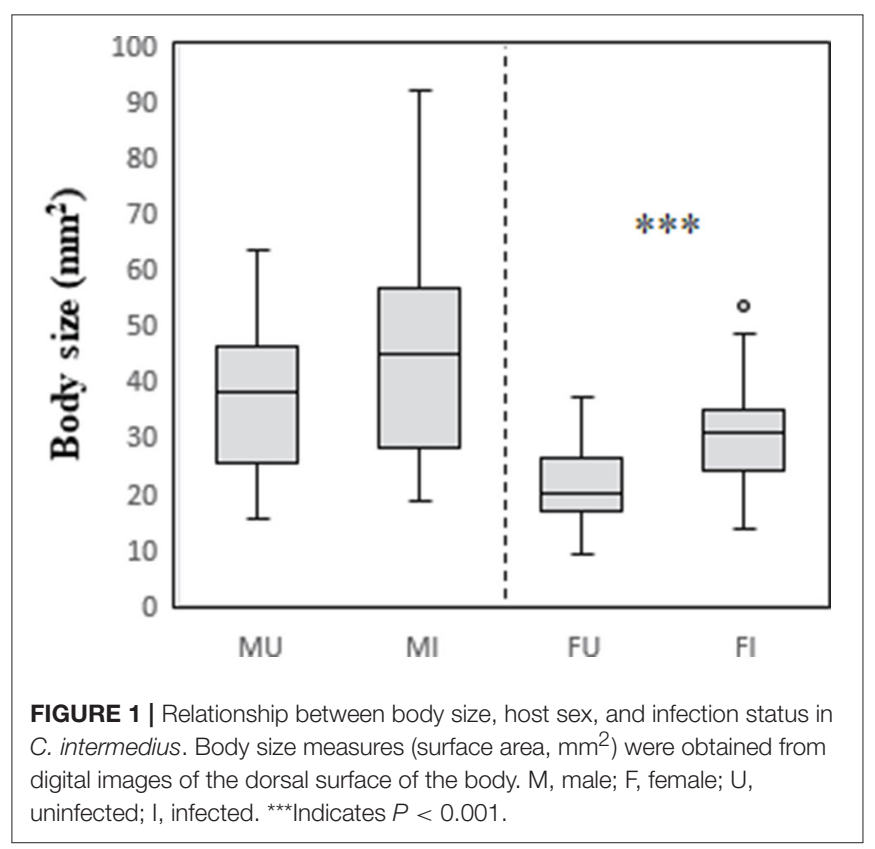



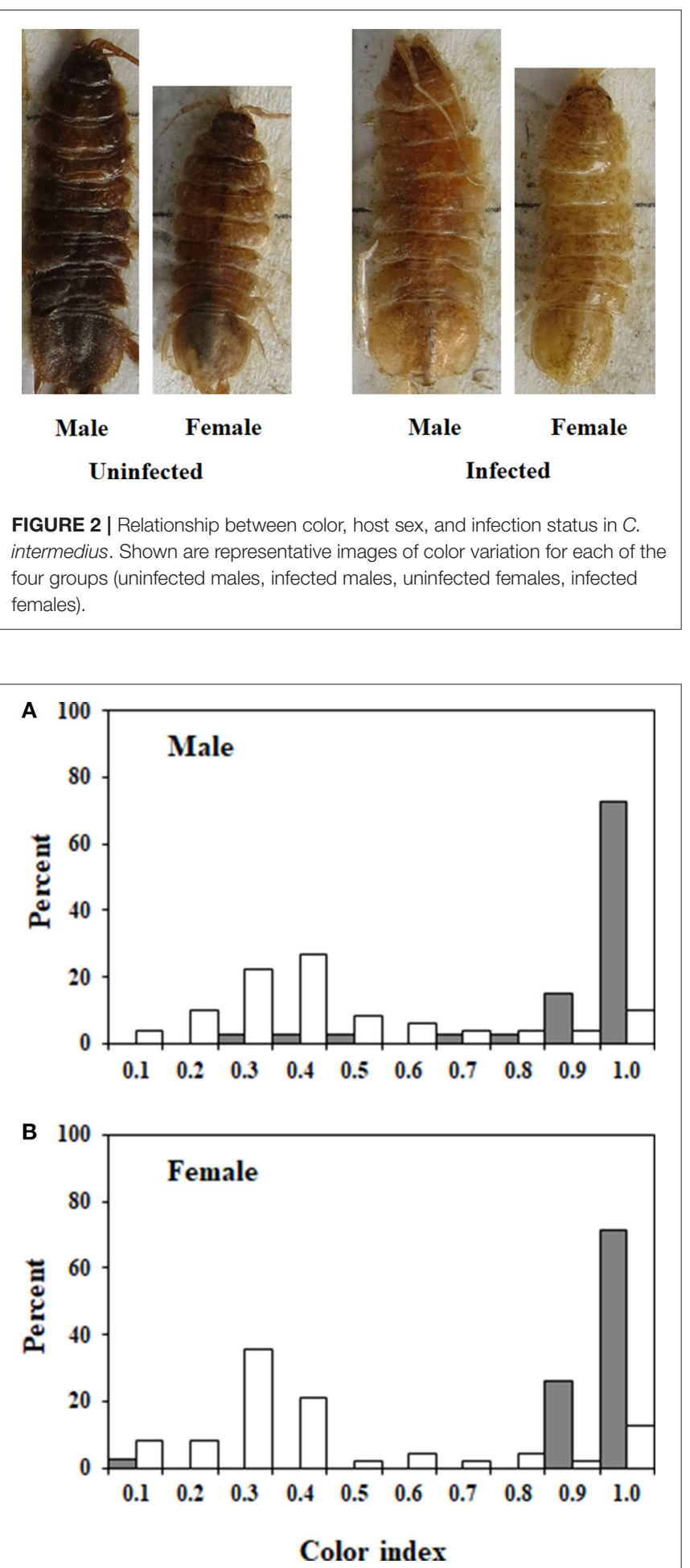

FIGURE 3 | Frequency distributions of color index values. Relative frequencies of color index measures for members of each of the four groups. (A) Uninfected and infected males. (B) Uninfected and infected females. Values ranged from 0 to 1 and represent measures of both color type and body coverage. A value of 1 represents an individual with dark brown coloration that is present over the entire dorsal surface of the body. Values for uninfected individuals are shown in gray and values for infected individuals are shown in white. (males: $U=214, d f=49,40, P<0.001$; females: $U=232, d f=$ $48,42, P<0.001)$.

Refuge use and activity showed sex-specific effects of infection (Table 2). Refuge use differed between infected and uninfected males $(U=732$, $d f=49,40, P<0.05)$ but not females $(U=$ $917, d f=48,42, P>0.05)$. In contrast, activity differed between infected and uninfected females $(U=666, d f=48,42, P>$ $0.05)$ but not males $(U=916, d f=49,40, P>0.05)$. Infected males spent less time in refuge than uninfected males and infected females were less active than uninfected females.

\section{Trait Correlations}

The relationships between trait-pairs for uninfected and infected males and females were assessed using Spearman correlation analysis (Table 3). For males, refuge use and body color were modified and these values were not correlated in either uninfected or infected individuals. For females, body color, activity, and body size were modified and only activity, and body color were correlated in uninfected individuals (i.e., dark-colored females were more active). However, this correlation was not retained in the laboratory $\left(r_{s}=-0.05, P>0.05\right)$. None of the modified traits were correlated in infected females. For the non-modified traits, correlations occurred between body size and refuge use, body size and activity, and body size and color in infected males. These correlations were not present in uninfected males. Excluding the relationship between body size and body color (i.e., traits measured in one location only), none of these correlations were retained in the laboratory (body size-refuge use, $r_{s}=-0.26, P>0.05$; body size-activity, $r_{s}=-0.15, P>$ 0.05).

\section{Plasticity and Consistency of Behavior}

Measures of plasticity and individual consistency of behavior are summarized in Table 4.

For the modified traits (male refuge use, female activity), there was plasticity in refuge use for both uninfected males (uninfected males, $z=3.7, P<0.001)$, and infected males $(z=5.0, P<$ $0.001)$, and there was plasticity in activity for uninfected females $(z=2.1, P<0.05)$ but not infected females $(z=0.6, P>0.05)$. The use of refuge was generally decreased in the laboratory (for both males and females) whereas activity was only decreased in the laboratory for one group (uninfected females).

Analysis of the measures of individual consistency for the modified traits revealed that activity generally showed higher levels of consistency than refuge use between the two situations (Table 4). For the modified traits, there was consistency in refuge use for infected males ( $W=0.74, d f=48, P<0.05$ ) but not uninfected males $(W=0.58, d f=39, P>0.05)$. Similarly, there was consistency in activity for infected females $(W=0.68, d f=$ $47, P<0.05)$ but not for uninfected females $(W=0.50, d f=41$, $P>0.05)$.

\section{Parasite Characteristics and Multidimensionality}

The relationships between parasite characteristics and multi-trait expression are summarized in Table 5. None of the traits that were modified in males or females were correlated with either 
TABLE 3 | Spearman correlation coefficients between traits for infected and uninfected male and female isopods.

\begin{tabular}{llcccc}
\hline Host sex & Trait & Body size & Refuge use & Activity & Color index \\
\hline \multirow{2}{*}{ Male } & Body size & - & -0.14 & -0.16 & 0.22 \\
& Refuge use & $-0.35^{\star}$ & - & -0.10 & 0.17 \\
& Activity & $-0.32^{*}$ & 0.20 & - & 0.09 \\
& Color index & $0.37^{*}$ & $-\mathbf{0 . 2 5}$ & -0.11 & - \\
Female & Body size & - & 0.05 & -0.18 & 0.04 \\
& Refuge use & -0.04 & - & -0.05 & 0.03 \\
& Activity & $\mathbf{0 . 0 9}$ & -0.13 & - & $0.38^{*}$ \\
& Color index & $-\mathbf{0 . 1 0}$ & -0.20 & $\mathbf{0 . 1 1}$ & -
\end{tabular}

Trait-pairs in which both traits were modified individually (Table 2) are shown in bold. Upper diagonals for each group show values for the uninfected individuals and lower diagonals (in italics) show values for infected individuals. *Indicates that the correlation was significant at the 0.05 level. Correlation analysis using principal component values for color (PC1) yielded similar relationships to those shown for the color index.

parasite intensity or parasite size. Parasite size was correlated with host size for male hosts. Parasite intensity and parasite size were not correlated with each other in either male hosts $\left(r_{\mathrm{s}}=0.007\right.$, $P>0.05)$ or female hosts $\left(r_{\mathrm{s}}=-0.08, P>0.05\right)$.

\section{DISCUSSION}

The importance of studying host modification from a multidimensional perspective has been emphasized in recent years (e.g., Cézilly and Perrot-Minnot, 2005, 2010; Thomas et al., 2005, 2010, 2012; Benesh et al., 2008; Poulin, 2010; Cézilly et al., 2013; Perrot-Minnot et al., 2014). The results obtained here showed that modification was multidimensional and that the pattern of multidimensionality was sex-specific. Infected male C. intermedius expressed less body color and were more likely to be located in the open than uninfected males. In contrast, infected females expressed less body color, were less active, and were larger than uninfected females. Analysis of the phenotypic correlations among traits showed that the modified traits were not typically correlated with each other indicating that trait modification appears to be occurring through independent mechanisms. Measures of plasticity and consistency of the behavioral traits showed that plasticity was generally high for refuge use and consistency was generally high for activity. Additionally, consistency increased for modified traits in both males (refuge use) and females (activity). Finally, there appeared to be no effect of competitive interactions among parasites on multidimensional modification for either male or female hosts. Figure 4 provides a visual representation of the major results obtained in the study and we discuss the implications of these findings to patterns of host modification in this as well as other host-parasite relationships below.

\section{Multidimensionality}

Multidimensionality refers to the modification of multiple host traits, which can occur either simultaneously or sequentially (Cézilly and Perrot-Minnot, 2005, 2010; Thomas et al., 2005, 2010, 2012; Cézilly et al., 2013). Thomas et al. (2010) proposed that traits should only be considered multidimensional if they are involved in the parasite transmission process. In contrast, Cézilly and Perrot-Minnot (2010) proposed that all traits that are manipulated by parasites should be included in the analysis of multidimensionality because they are part of an infection syndrome. In the current study, we examined four traits (body color, body size, activity, refuge use) that have been shown to be associated with predation in other studies (body color-(Hargeby et al., 2004, 2005); refuge use and activity-(Holomuzki and Short, 1988; Huang and Sih, 1990); body size-(Holomuzki and Short, 1990); Sparkes 1996). There is also direct evidence that infected $C$. interemedius are more likely to be consumed by predatory definitive hosts than uninfected individuals (Camp and Huizinga, 1979). Thus, trait modification may be directly linked to trophic transmission in this system, which also appears to be the case in other isopod-acanthocephalan systems (e.g., Asellus aquaticus-Acanthocephalus lucii, (Brattey, 1983); Plagiorhynchus cylindraceus-Armadillidium vulgare, Moore, 1983).

In terms of the specific results obtained here, we found that multidimensionality occurred in both sexes but that the pattern of multidimensionality differed between the sexes. Body color was the only trait examined that was modified in a similar manner in both sexes. The decrease in expression of color identified in infected individuals would increase conspicuousness of the infected individuals against the dark-colored sediment of the stream. This elevated conspicuousness is expected to increase predation (Hargeby et al., 2004), and hence favor transmission to definitive hosts (Camp and Huizinga, 1979). Detailed analysis of the pigment changes associated with this color change have revealed that the modification appears to be due to either an interference of existing pigment pathways or a regulation of these pathways (referred to as pigment dystrophy, Oetinger and Nickol, 1981, 1982a). In this mechanism, the developing parasites compete with the host for amino acids, which in turn acts as a constraint on pigment production (Oetinger and Nickol, 1982a). If this is the case, then the body color of infected isopods may be an indirect effect of pathology that is associated with nutrient acquisition and the effect of the color change on predation would likely be secondary (i.e., it is an exaptation, Gould and Vrba, 1982; Thomas et al., 2012). A similar pattern of pigment dystrophy has been described in Brazilian populations of the terrestrial isopod Atlantoscia floridana infected with the acanthocephalan (Centrorhynchus sp., Amato et al., 2003).

Parasite-related changes in body size, refuge use and activity exhibited sex-specific effects in which infected females were larger and less active than uninfected females and infected males spent less time in refuge than uninfected males. If these changes are due to parasite infection, then these differences likely indicate that $A$. dirus parasites adopt different strategies of exploitation in male and female hosts. One obvious difference between male and female $C$. intermedius that could potentially influence exploitation is that there is significant size dimorphism between the sexes. Males are substantially larger than females. As a consequence, a parasite that establishes in a juvenile female could potentially have its later growth constrained by the small body size of the female during the adult stage. This type of effect could be costly because body size influences 
TABLE 4 | Estimates of plasticity and consistency for each behavior measured in two situations (immediately after collection at the field site, $24 \mathrm{~h}$ after collection in the laboratory).

\begin{tabular}{|c|c|c|c|c|c|c|}
\hline Host sex & Behavior & Infection status & Field site & Laboratory & Plasticity & Consistency \\
\hline \multirow[t]{4}{*}{ Male } & Refuge use & Uninfected & $67(17,100)$ & $0(0,58)$ & $\mathbf{P}$ & - \\
\hline & & Infected & $33(0,87)$ & $0(0,0)$ & $\mathbf{P}$ & C \\
\hline & Activity & Uninfected & $115(28,198)$ & $94,(44,168)$ & - & $\mathrm{C}$ \\
\hline & & Infected & $88(10,188)$ & $75(18,165)$ & - & C \\
\hline \multirow[t]{4}{*}{ Female } & Refuge use & Uninfected & $67(33,96)$ & $17(0,67)$ & $\mathrm{P}$ & C \\
\hline & & Infected & $50(17,87)$ & $0(0,0)$ & $\mathrm{P}$ & - \\
\hline & Activity & Uninfected & $158(70,208)$ & $90(45,160)$ & $\mathbf{P}$ & - \\
\hline & & Infected & $68(12,158)$ & $100(20,205)$ & - & C \\
\hline
\end{tabular}

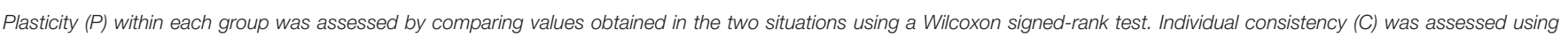
Kendall's coefficient of concordance. Traits that were modified individually are shown in bold.

TABLE 5 | Relationships between intensity of infection (mean number of $A$. dirus per infected host), parasite size (mean volume) and trait expression in male ( $n=$ 49) and female $(n=48)$ C. intermedius.

\begin{tabular}{llcc}
\hline Host sex & Host trait & Parasite intensity & Parasite size \\
\hline Male & Body size & 0.20 & $0.56^{\star \star \star}$ \\
& Refuge use & 0.15 & -0.17 \\
& Activity & 0.03 & -0.06 \\
Female & Color index & -0.12 & 0.13 \\
& Body size & 0.10 & 0.05 \\
& Refuge use & 0.13 & -0.01 \\
& Activity & -0.21 & -0.10 \\
& Color index & -0.15 & -0.09
\end{tabular}

Shown are Spearman correlation coefficients with modified traits emphasized in bold. ${ }^{* \star \star} /$ ndicates $P<0.001$. Analysis using principal component values for color (PC1) yielded similar relationships to those shown for color index.

establishment success, mate choice, male-male competition and female fecundity in acanthocephalans (Lawlor et al., 1990; Poulin and Morand, 2000; Dezfuli et al., 2002; Steinauer and Nickol, 2003). Thus, parasites that establish in females may be under stronger selection than those that establish in males to exploit the hosts in ways that favor their own growth and development (e.g., Baudoin, 1975). One outcome of this type of effect could be that the parasites modify growth of females, but not males, so that the body size of the female is increased during the adult stage to provide more space for the parasite (Baudoin, 1975). Consistent with this hypothesis, infected female $C$. intermedius were larger than uninfected females whereas there was no difference in body size between infected and uninfected males. In addition, there was no difference in body size of the A. dirus parasites recovered from female hosts and male hosts. Thus, a sex-specific strategy of exploitation that allows for optimal parasite growth may explain the difference in body size between the sexes (see Table 1 for other examples).

In addition to effects of $A$. dirus infection on host growth described above, other traits may be influenced by this type of sex-specific strategy of exploitation if they also facilitate parasite growth. For example, acanthocephalans often induce pathological and irreversible effects on female reproduction but have negligible effects on male reproduction (e.g., Dezfuli et al., 2008). One explanation for this type of sex-specific effect on females is that the energy that would have been allocated to reproduction can be reallocated for both host and parasite growth (Baudoin, 1975). Consistent with this hypothesis, infected female $C$. intermedius were less active than uninfected females but there was no difference in activity between infected and uninfected males. This decrease in activity could also favor parasites that infect females by increasing parasite and host growth. In contrast, a decrease in activity seems unlikely to favor transmission since decreased activity levels are typically expected to decrease predation risk (Camp and Huizinga, 1979; Holomuzki and Short, 1988; Huang and Sih, 1990; Dezfuli et al., 2003). Thus, the decrease in activity in infected females is more consistent with a pathological effect of infection than it is with adaptive manipulation. A third possibility is that a decrease in activity is a host counteradaptation (e.g., Minchella, 1985; Poulin et al., 1994). This explanation seems unlikely in this system since there is no evidence that adult isopods can mount an immune defense against cystacanths at this stage (9-11 months post-infection), adult females are close to the ends of their lives and effects on female reproduction appear to be irreversible. Thus, there are no obvious fitness payoff to females for suppressing their own activity.

Sex-specific effects of infection were also identified for refuge use. For males, infected individuals spent less time in refuge than uninfected males whereas there was no difference in refuge use between infected and uninfected females. Refuge use, like body color, is expected to influence conspicuousness of isopods by affecting the amount of time individuals are exposed to predators (Holomuzki and Short, 1988; Huang and Sih, 1990). Previous research has shown that infected $C$. intermedius that leave refuge do not do so to feed (Hechtel et al., 1993) and that infected male $C$. intermedius are in good physiological condition relative to uninfected males (Korkofigas et al., 2016). Thus, changes in refuge use do not appear to be due to a simple pathological effect on energy reserves. In addition, the modification of host microhabitat use, which includes refuge use, appears to be widespread in acanthocephalans (Poulin, 1994b). Collectively, 


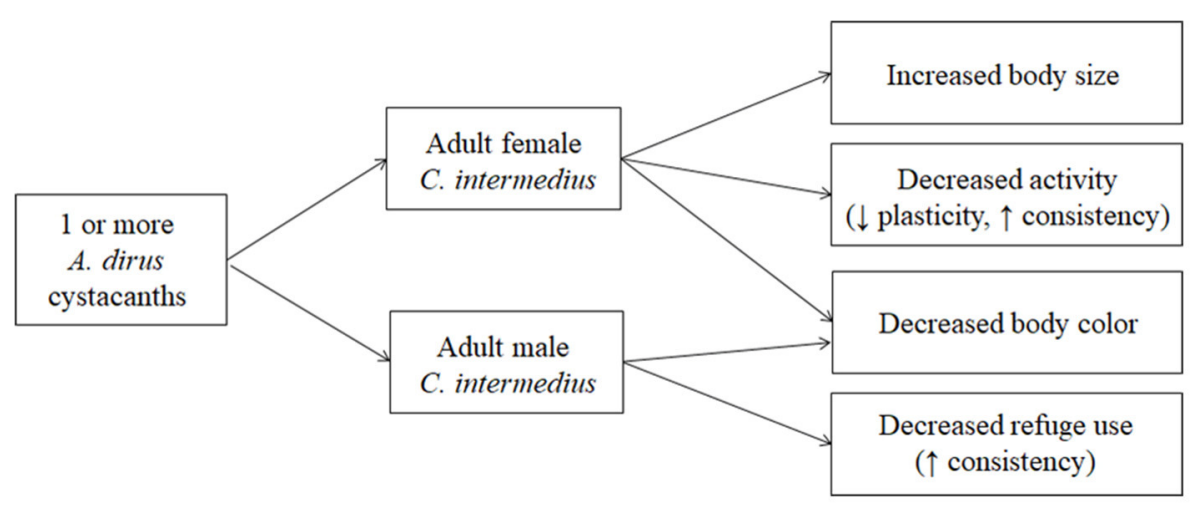

FIGURE 4 | Summary of results obtained for multidimensional modification in $C$. intermedius. Patterns of modification differed between the sexes but were not affected by variation in parasite intensity. A decrease in body color was the only trait modified in both sexes. Measures of plasticity and individual consistency were obtained for activity and refuge use in two situations (field site, laboratory).

these results likely indicate that the modification of refuge use in males is due to parasitic manipulation.

In sum, the pattern of trait modification in C. intermedius is multidimensional and sex-specific. Infected males undergo changes in body color and refuge use whereas infected females undergo changes in body color, body size, and activity. Modification of body color, body size and activity appear to be associated either directly or indirectly with pathological effects of infection. In contrast, modification of refuge use is more likely to be explained by parasitic manipulation. The modification of body color in males and females, body size in females, and refuge use in males have the potential to influence transmission by increasing the conspicuousness of infected individuals to predatory definitive hosts.

\section{Multidimensionality and Trait Correlations}

Phenotypic correlations among trait-pairs can provide insights into multidimensional modification because they can be used to determine if the proximate mechanisms underlying modification are shared among traits (Cézilly and Perrot-Minnot, 2005). In acanthocephalans, there is growing evidence that multiple neurological systems are involved in the modification of multiple host traits and that the serotonergic and dopaminergic systems may be the favored systems (Adamo, 2012; Lafferty and Shaw, 2013; Perrot-Minnot and Cézilly, 2013). There is also evidence that individual systems can modulate multiple traits indicating that some proximate mechanisms have shared effects (Perrot-Minnot et al., 2014). Previous research on the $C$. intermedius $-A$. dirus relationship has shown that both serotonin and dopamine levels differ between infected and uninfected C. intermedius indicating the potential for both the serotonergic and dopaminergic systems to play a role in multidimensional modification (Kopp et al., 2016). However, results of the analysis of trait correlations revealed that none of the modified traits were correlated with each other in infected individuals. In addition, any traits that were correlated at the field site (e.g., activity and body color of uninfected females) were not correlated in the laboratory. Thus, it appears that modification of the traits examined here occurred through independent proximate mechanisms.

Poulin (2010) proposed that the correlations among traits may by the true targets of manipulation in cases where the parasites benefit by either disrupting existing correlations or creating new correlations between traits (see also Barber and Dingemanse, 2010; Coats et al., 2010; Hammond-Tooke et al., 2012; Poulin, 2013). Population-level correlations among different traits or the same trait in different contexts have been described as behavioral syndromes (Sih et al., 2004; Poulin, 2013) and there is evidence that parasites can influence these syndromes in some cases (Coats et al., 2010; Hammond-Tooke et al., 2012; Seaman and Briffa, 2015). If parasites disrupt trait correlations in the C. intermediusA. dirus relationship, then the only candidate is the correlation that occurred between color and activity in uninfected females. Uninfected females that were more darkly-colored were also more active but this relationship was not present in infected females. Since both of these traits are modified, it seems plausible to suggest that the correlation may have been targeted by parasites. However, it should also be noted that this correlation was not present in the laboratory for uninfected females. If parasites create new correlations, then the relationships between body size and each of the other traits examined may have been targeted since they were correlated in infected males but not in uninfected males. Again though, these relationships were not present in the laboratory (excluding body size-body color, which was only measured in one situation) and body size and refuge use were not modified traits in males. Given the discussion above concerning the independent nature of proximate mechanisms underlying modification, it may be the case that trait correlations are not targeted in this host-parasite relationship.

\section{Multidimensionality, Plasticity and Consistency}

Most studies that examine host modification in acanthocephalans do so in laboratory-based settings but little is known about the levels of plasticity and consistency that occur between different situations. The results obtained concerning the analysis of 
behavior modification (male refuge use, female activity) between situations (field site immediately after collection, laboratory 24 $h$ later) revealed that the patterns of plasticity and consistency differed between males and females and between infected and uninfected $C$. intermedius. Refuge use in males exhibited plasticity in both uninfected and infected individuals with lower values of refuge use being expressed in the laboratory than at the field site. In contrast, activity exhibited plasticity in uninfected females between situations but not in infected females. Measures of individual consistency revealed that consistency was present for the modified traits in infected individuals but not in uninfected individuals. Thus, infection appeared to be associated with an increase in consistency of the modified behaviors. Traits that show consistency can be considered components of animal personalities (e.g., Réale et al., 2007, 2010; Barber and Dingemanse, 2010; Poulin, 2013) and there is evidence that crustaceans, and other invertebrates, can have distinct personalities (Briffa et al., 2008; Mowles et al., 2012; Seaman and Briffa, 2015). The results obtained here indicate that $A$. dirus infection may be shaping personalities in $C$. intermedius by increasing consistency of the modified traits. Consistent with these findings, parasite-related changes in consistency have also been identified in other systems (e.g., Hammond-Tooke et al., 2012).

\section{Parasite Characteristics and Multidimensionality}

Competitive interactions between parasites that share a host have the potential to influence trait modification if they affect the strategy of manipulation adopted by the parasites. A change in the strategy of manipulation may be expected if host manipulation is energetically costly and if the competitive interactions influence the amount of resources each parasite has available to allocate to manipulation (Dianne et al., 2012; Caddigan et al., 2014, 2017). Previous research on the population studied here has shown that mating behavior is suppressed in infected male $C$. intermedius relative to uninfected males and that this suppression is less likely to occur at higher parasite intensities, i.e., when intraspecific competition is more intense (Caddigan et al., 2014). In this relationship, intraspecific competition does not appear to influence parasite size (Caddigan et al., 2017; Table 5 this study) but does influence parasite energy content (Caddigan et al., 2017). Specifically, glycogen levels per parasite decrease by $\sim 80 \%$ and lipid levels per parasite decrease by $\sim 20 \%$ at higher parasite intensities relative to single infections. Given the magnitude of these energy-based costs, it seems likely that if manipulation was energetically costly then modification of host traits should be less likely to occur at higher parasite intensities. Contrary to this prediction, we found that parasite intensity was not associated with host modification for any of the traits examined. Thus, intraspecific competition did not appear to act as a constraint on host modification. This result is consistent with the interpretation that trait modification may carry either negligible or no physiological costs in many cases (Poulin et al., 2005; Thomas et al., 2005). Similar patterns between parasite intensity and multidimensionality have also been described in the European isopod A. aquaticus infected by the acanthocephalan A. lucii (Benesh et al., 2008). However, it should be noted that that mean intensity was lower in the current study (1.4) than in the previous studies (2.5) in which an intensity-related effect was identified (Caddigan et al., 2014, 2017). Thus, it is possible that intensity-related effects are present but occur at higher intensities than were examined here.

Benesh et al. (2008) provided the only other analysis of multidimensionality in an isopod-acanthocephalan system. In their study, five traits were examined (activity, hiding behavior, substrate preference, body color, abdomen color) in male and female $A$. aquaticus that were infected with the acanthocephalan A. lucii. There is some overlap between the results obtained in this study and the results obtained here. For example, hiding behavior and abdominal coloration differed between uninfected and infected individuals and variation in these modified traits occurred independently indicating that the mechanisms underlying modification appeared to differ between the modified traits. This study also found that the intensity of infection was not associated with trait expression, that hiding behavior had low levels of repeatability and that activity levels had higher repeatability levels for infected individuals than uninfected individuals. However, several results differed between the two systems. Specifically, we found that the pattern of multidimensional modification was sex-specific in the $C$. intermedius $-A$. dirus relationship whereas the pattern of multidimensional modification did not differ between the sexes in the $A$. aquaticus- $A$. lucii relationship. In addition, activity was a modified trait in the current study for females but activity was not a modified trait in $A$. aquaticus. Finally, the type of color change that occurred in A. aquaticus resulted in a darkening of abdominal coloration only. In $C$. intermedius, body coloration changed to a lighter color and occurred over the entire body in infected individuals. In nature, both types of color change are expected to increase conspicuousness to definitive hosts by decreasing crypsis.

\section{Natural Infections}

A potential concern with the study presented here is that that none of the hosts examined were infected experimentally. Thus, it is possible that differences in trait expression identified between uninfected and infected isopods were due to preexisting differences between the groups. It is also possible that these effects may have caused the differences in infection status identified if they increased the risk of infection occurring (see Barber and Dingemanse, 2010 for discussion). Contrary to this explanation, differences in body color and behavior have been shown to be associated with $A$. dirus development in C. intermedius (Sparkes et al., 2004, 2006) and experimental infections of $C$. intermedius with $A$. dirus parasites have shown that changes in body color are induced that are similar to those that occur in nature (Oetinger and Nickol, 1982b) Further, host modification appears to be an ancestral trait in acanthocephalans (Moore, 1984; Thomas et al., 2012) and experimental infections of other isopods and amphipods have 
demonstrated that the modification of body color, body size, and behavior is infection-dependent (e.g., Benesh and Valtonen, 2007b; Hasu et al., 2007; Franceschi et al., 2008, 2010; Benesh et al., 2009a; Dianne et al., 2011). Finally, given the high levels of behavioral plasticity that occurred between the two situations examined in C. intermedius (Table 4), behavioral measures obtained in the laboratory, which would be obtained several months after experimental infection, may not represent those that would be expressed in nature. Thus, the approach presented here, in which measures of behavior were recorded both at the field site as well as the laboratory, may be preferred in this case.

\section{AUTHOR CONTRIBUTIONS}

TP and TS designed the experiments and completed a pilot study in the field and laboratory. TP ran the field and laboratory components of the experiment and collected the raw data. TP

\section{REFERENCES}

Adamo, S. A. (2012). “The strings of the puppet master: how parasites change host behavior," in Host Manipulation by Parasites, eds D. P. Hughes, J. Brodeur, and F. Thomas (Oxford, UK: Oxford University Press), 36-51.

Adamo, S. A. (2013). Parasites: evolution's neurobiologists. J. Exp. Biol. 216, 3-10. doi: $10.1242 /$ jeb.073601

Amato, J. F. R., Amato, S. B., Arauja, P. B., and Quadros, A. F. (2003). First report of pigmentation dystrophy in terrestrial isopods, Atlantoscia floridana (van Name) (Isopoda, Oniscidea), induced by larval acanthocephalans. Rev. Bras. Zool. 20, 711-716. doi: 10.1590/S0101-81752003000400026

Ball, M. A., Parker, G. A., and Chubb, J. C. (2008). The evolution of complex life cycles when parasite mortality is size- or time-dependent. J. Theor. Biol. 253, 202-214. doi: 10.1016/j.jtbi.2008.02.025

Barber, I., and Dingemanse, N. J. (2010). Parasitism and the evolutionary ecology of animal personality. Philos. Trans. R. Soc. B 365, 4077-4088. doi: $10.1098 /$ rstb.2010.0182

Baudoin, M. (1975). Host castration as a parasitic strategy. Evolution 29, 335-352. doi: 10.1111/j.1558-5646.1975.tb00213.x

Benesh, D. P., and Valtonen, E. T. (2007a). Proximate factors affecting the larval life history of Acanthocephalus lucii (Acanthocephala). J. Parasitol. 93, 742-749. doi: 10.1645/GE-1094R.1

Benesh, D. P., and Valtonen, E. T. (2007b). Effects of Acanthocephalus lucii (Acanthocephala) on intermediate host survival and growth: implications for exploitation strategies. J. Parasitol. 93, 735-741. doi: 10.1645/GE-1093R.1

Benesh, D. P., Hasu, T., Seppälä, O., and Valtonen, E. T. (2009b). Seasonal changes in host phenotype manipulation by an acanthocephalan: time to be transmitted? Parasitology 136, 219-230. doi: 10.1017/S0031182008005271

Benesh, D. P., Seppälä, O., and Valtonen, E. T. (2009a). Acanthocephalan size and sex affect the modification of intermediate host colouration. Parasitology 136, 847-854. doi: 10.1017/S0031182009006180

Benesh, D. P., Valtonen, E. T., and Seppälä, O. (2008). Multidimensionality and intra-individual variation in host manipulation by an acanthocephalan. Parasitology 135, 617-626. doi: 10.1017/S0031182008004216

Bierbower, S. M., and Sparkes, T. C. (2007). Parasite-related pairing success in an intermediate host, Caecidotea intermedius (Isopoda): effects of male behavior and reproductive physiology. J. Parasitol. 93, 445-449. doi: 10.1645/GE-960R1.1

Brattey, J. (1983). The effects of larval Acanthocephalus lucii on the pigmentation, reproduction, and susceptibility to predation of the isopod Asellus aquaticus. J. Parasitol. 69, 1172-1173. doi: 10.2307/3280892

Briffa, M., Rundle, S. D., and Fryer, A. (2008). Comparing the strength of behavioural plasticity and consistency across situations: animal personalities and TS contributed equally to the analysis and writing of the manuscript.

\section{FUNDING}

Department of Biological Sciences, University Research Council (Competitive Research Grant) and a Faculty Summer Research Grant (DePaul University).

\section{ACKNOWLEDGMENTS}

Sara Teemer, Melissa Horther, Andrew Steffen, Emma Schremp, and Erica Valdez assisted in data collection. Windsor Aguirre and Kenshu Shimada provided valuable comments as members of the thesis committee on an earlier version of this work. This earlier version was produced as a thesis, which partially met the requirements of the MS degree in Biological Sciences at DePaul University. in the hermit crab Pagurus bernhardus. Proc. R. Soc. B. 275, 1305-1311. doi: 10.1098/rspb.2008.0025

Bush, A. O., Lafferty, K. D., Lotz, J. M., and Shostak, A. W. (1997). Parasitology meets ecology on its own terms: Margolis et al. revisited. J. Parasitol. 83, 575-583. doi: 10.2307/3284227

Caddigan, S. C., Barkauskas, R. T., and Sparkes, T. C. (2014). Intra-population variation in behavior modification by the acanthocephalan Acanthocephalus dirus: are differences mediated by host condition? Parasitol. Res. 113, 4307-4311. doi: 10.1007/s00436-014-4137-9

Caddigan, S. C., Pfenning, A. C., and Sparkes, T. C. (2017). Competitive growth, energy allocation, and host modification in the acanthocephalan Acanthocephalus dirus: field data. Parasitol. Res. 116, 199-206. doi: 10.1007/s00436-016-5279-8

Camp, J. W., and Huizinga, H. W. (1979). Altered color, behavior and predation susceptibility of the isopod Asellus intermedius infected with Acanthocephalus dirus. J. Parasitol. 65, 669-671. doi: 10.2307/3280340

Camp, J. W., and Huizinga, H. W. (1980). Seasonal population interactions of Acanthocephalus dirus (Van Cleave 1931) in the creek chub, Semotilus atromaculatus, and isopod, Asellus intermedius. J. Parasitol. 66, 299-304. doi: $10.2307 / 3280822$

Cézilly, F., and Perrot-Minnot, M.-J. (2005). Studying adaptive changes in the behaviour of infected hosts: a long and winding road. Behav. Process. 68, 223-228. doi: 10.1016/j.beproc.2004.08.013

Cézilly, F., and Perrot-Minnot, M.-J. (2010). Interpreting multidimensionality in parasite-induced phenotypic alterations: panselectionism versus parsimony. Oikos 119, 1224-1229. doi: 10.1111/j.1600-0706.2010.18579.x

Cézilly, F., Favrat, A., and Perrot-Minnot, M.-J. (2013). Multidimensionality in parasite-induced phenotypic alterations: ultimate versus proximate aspects. J. Exp. Biol. 216, 27-35. doi: 10.1242/jeb.074005

Coats, J., Poulin, R., and Nakagawa, S. (2010). The consequences of parasitic infections for host behavioural correlations and repeatability. Behaviour 147, 367-382. doi: 10.1163/000579509X12574307194101

Dezfuli, B. S., Giari, L., and Poulin, R. (2001). Costs of intraspecific and interspecific host sharing in acanthocephalan cystacanths. Parasitology 122, 483-489. doi: 10.1017/S0031182001007454

Dezfuli, B. S., Lui, A., Giovinazzo, G., and Giari, L. (2008). Effect of Acanthocephala infection on the reproductive potential of crustacean intermediate hosts. J. Invert. Pathol. 98, 116-119. doi: 10.1016/j.jip.2007.11.003

Dezfuli, B. S., Maynard, B. J., and Wellnitz, T. A. (2003). Activity levels and predator detection by amphipods infected with an acanthocephalan parasite, Pomphorhynchus laevis. Folia Parasitol. 50, 129-134. doi: 10.14411/fp.2003.023

Dezfuli, B. S., Rossetti, E., and Fano, E. A. (1994). Occurrence of larval Acanthocephalus anguillae (Acanthocephala) in the Asellus aquaticus 
(Crustacea, Isopoda) from the River Brenta. Biol. Zool. 61, 77-81. doi: 10.1080/11250009409355862

Dezfuli, B. S., Volponi, S., Beltrami, I., and Poulin, R. (2002). Intra- and interspecific density-dependent effects on growth in helminth parasites of the cormorant Phalacrocorax carbo sinensis. Parasitology 124, 537-544. doi: 10.1017/S0031182002001555

Dianne, L., Bollache, L., Lagrue, C., Franceschi, N., and Rigaud, T. (2012). Larval size in acanthocephalan parasites: influence of intraspecific competition and effects on intermediate host behavioural changes. Parasit. Vectors 5:166. doi: 10.1186/1756-3305-5-166

Dianne, L., Perrot-Minnot, M.-J., Bauer, A., Gaillard, M., Léger, W., and Rigaud, T. (2011). Protection first then facilitation: a manipulative parasite modulates the vulnerability to predation of its intermediate host according to its own developmental stage. Evolution 65, 2692-2698. doi: 10.1111/j.1558-5646.2011.01330.x

Dianne, L., Rigaud, T., Léger, E., Motreuil, S., Bauer, A., and Perrot-Minnot, M.-J. (2010). Intraspecific conflict over host manipulation between different larval stages of an acanthocephalan parasite. J. Evol. Biol. 23, 2648-2655. doi: 10.1111/j.1420-9101.2010.02137.x

Franceschi, N., Bauer, A., Bollache, L., and Rigaud, T. (2008). The effects of parasite age and intensity on variability in acanthocephalan-induced behavioural manipulation. Int. J. Parasitol. 38, 1161-1170. doi: 10.1016/j.ijpara.2008.01.003

Franceschi, N., Bollache, L., Cornet, S., Bauer, A., Motreuil, S., and Rigaud, T. (2010). Co-variation between the intensity of behavioural manipulation and parasite development time in an acanthocephalan-amphipod system. J. Evol. Biol. 23, 2143-2150. doi: 10.1111/j.1420-9101.2010.02076.x

Gould, S. J., and Vrba, E. S. (1982). Exaptation: a missing term in the science of form. Paleobiology 8, 4-15. doi: 10.1017/S0094837300004310

Hammond-Tooke, C. A., Nakagawa, S., and Poulin, R. (2012). Parasitism and behavioural syndromes in the fish Gobiomorphus cotidianus. Behaviour 149, 601-622. doi: 10.1163/156853912X648903

Hargeby, A., Johansson, J., and Ahnesjö, J. (2004). Habitat-specific pigmentation in a freshwater isopod: adaptive evolution over a small spatiotemporal scale. Evolution 58, 81-94. doi: 10.1111/j.0014-3820.2004.tb01575.x

Hargeby, A., Stoltz, J., and Johansson, J. (2005). Locally differentiated cryptic pigmentation in the freshwater isopod Asellus aquaticus. J. Evol. Biol. 18, 713-721. doi: 10.1111/j.1420-9101.2004.00837.x

Hasu, T. (2013). Host-Related Factors Affecting Isopod (Asellus aquaticus) Susceptibility to and Interaction with an Acanthocephalan (Acanthocephalus lucii) Parasite. Master's thesis. Jyväskylä: University of Jyväskylä.

Hasu, T., Holmes, J. C., and Valtonen, E. T. (2007). Isopod (Asellus aquaticus) size and acanthocephalan (Acanthocephalus lucii) infections. J. Parasitol. 93, 450-457. doi: 10.1645/GE-1032R.1

Hechtel, L. J., Johnson, C. L., and Juliano, S. A. (1993). Modification of antipredator behavior of Caecidotea intermedius by its parasite Acanthocephalus dirus. Ecology 74, 710-713. doi: 10.2307/1940798

Hernandez, A. D., and Sukhdeo, M. V. K. (2008). Parasite effects on isopod feeding rates can alter the host's functional role in a natural stream ecosystem. Int. J. Parasitol. 38, 683-690. doi: 10.1016/j.ijpara.2007.09.008

Holomuzki, J. R., and Short, T. (1988). Habitat use and fish avoidance behaviors by the stream-dwelling isopod Lirceus fontinalis. Oikos 52, 79-86. doi: $10.2307 / 3565985$

Holomuzki, J. R., and Short, T. (1990). Ontogenetic shifts in habitat use and activity in a stream-dwelling isopod. Holarct. Ecol. 13, 300-307. doi: 10.1111/j.1600-0587.1990.tb00622.x

Huang, C., and Sih, A. (1990). Experimental studies on behaviorally mediated, indirect interactions through a shared predator. Ecology 71, 1515-1522. doi: $10.2307 / 1938288$

Hughes, D. P., Brodeur, J., and Thomas, F. (2012). Host Manipulation by Parasites. Oxford: Oxford University Press.

Kakizaki, T., Saito, T., Ohtaka, A., and Nagasawa, K. (2003). Effects of Acanthocephalus sp. (Acanthocephala: Echinorhynchidae) on the body size and reproduction of isopods (Asellus hilgendorfi). Limnology 4, 43-36. doi: 10.1007/s10201-002-0090-x

Kaldonski, N., Perrot-Minnot, M.-J., Dodet, R., Martinaud, G., and Cézilly, F. (2009). Carotenoid-based colour of acanthocephalan cystacanths plays no role in host manipulation. Proc. R. Soc. B. 276, 169-176. doi: 10.1098/rspb.2008.0798
Kennedy, C. R. (2006). Ecology of the Acanthocephala. New York, NY: Cambridge University Press.

Keogh, D. P., and Sparkes, T. C. (2003). Sexual contests in aquatic crustaceans: what's physiology got to do with it? Am. Biol. Teach. 65, 47-52. doi: 10.1662/ 0002-7685(2003)065[0047:SCIACW]2.0.CO;2

Kopp, D. A., Bierbower, S. M., Murphy, A. D., Mormann, K., and Sparkes, T. C. (2016). Parasite-related modification of mating behaviour and refuge use in the aquatic isopod Caecidotea intermedius: neurological correlates. Behaviour 153, 947-961. doi: 10.1163/1568539X-00003379

Korkofigas, E. (2007). Mechanisms Underlying Parasite-Related Suppression of Mating Behavior in the Intermediate Host, Caecidotea intermedius (Isopoda): Behavior and Physiology. Master's thesis. Chicago, IL: DePaul University.

Korkofigas, E., Park, T., and Sparkes, T. C. (2016). Acanthocephalanrelated variation in the pattern of energy storage of a behaviorally and physiologically modified host: field data. Parasitol. Res. 115, 339-345. doi: 10.1007/s00436-015-4753-z

Lafferty, K. D., and Shaw, J. C. (2013). Comparing mechanisms of host manipulation across host and parasite taxa. J. Exp. Biol. 216, 56-66. doi: 10.1242/jeb.073668

Lagrue, C., Kaldonski, N., Perrot-Minnot, M.-J., Motreuil, S., and Bollache, L. (2007). Modification of hosts' behavior by a parasite: field evidence for adaptive manipulation. Ecology 88, 2839-2847. doi: 10.1890/06-2105.1

Lawlor, B. J., Read, A. F., Keymar, A. E., Parveen, G., and Crompton, D. W. T. (1990). Non-random mating in a parasitic worm: mate choice by males? Anim. Behav. 40, 870-876. doi: 10.1016/S0003-3472(05)80988-1

Lefèvre, T., Adamo, S. A., Biron, D. G., Missé, D., Hughes, D., and Thomas, F. (2009). Invasion of the body snatchers: the diversity and evolution of manipulation strategies in host-parasite interactions. Adv. Parasitol. 68, 45-83. doi: 10.1016/S0065-308X(08)00603-9

Lenneberg, E. H., and Roberts, J. M. (1956). The Language of Experience: A Study in Methodology. Montana, MT: Literary Licensing, L.L.C.

Lentner, M., and Bishop, T. (1986). Experimental Design and Analysis. Virginia, VA: Valley Book Company.

Lettini, S. E., and Sukhdeo, M. V. K. (2010). The energetic cost of parasitism in isopods. Ecoscience 17, 1-8. doi: 10.2980/17-1-3276

Lyndon, A. R. (1996). "The role of acanthocephalan parasites in the predation of freshwater isopods by fish," in Aquatic Predators and their Prey, eds S. P. R. Greenstreet and M. L. Tasker (Oxford, UK: Fishing News Books), 26-32.

Maure, F., Brodeur, J., Hughes, D., and Thomas, F. (2013). How much energy should manipulative parasites leave to their hosts to ensure altered behaviours? J. Exp. Biol. 216, 43-46. doi: 10.1242/jeb.073163

Michaud, M., Milinski, M., Parker, G. A., and Chubb, J. C. (2006). Competitive growth strategies in intermediate hosts: experimental tests of parasite lifehistory model using the cestode, Schistocephalus solidus. Evol. Ecol. 20, 39-57. doi: 10.1007/s10682-005-3274-0

Minchella, D. J. (1985). Host life-history variation in response to parasitism. Parasitology 90, 205-216. doi: 10.1017/S0031182000049143

Moore, J. (1983). Responses of an avian predator and its isopod prey to an acanthocephalan parasite. Ecology 64, 1000-1015. doi: 10.2307/1937807

Moore, J. (1984). Altered behavioral responses in intermediate hosts-an acanthocephalan strategy. Am. Nat. 123, 572-577. doi: 10.1086/284224

Moore, J. (2002). Parasites and the Behavior of Animals. New York, NY: Oxford University Press.

Mowles, S. L., Cotton, P. A., and Briffa, M. (2012). Consistent crustaceans: the identification of stable behavioural syndromes in hermit crabs. Behav. Ecol. Sociobiol. 66, 1087-1094. doi: 10.1007/s00265-012-1359-7

Muzzall, P. M., and Rabalais, F. C. (1975a). Studies on Acanthocephalus jacksoni Bullock, 1962 (Acanthocephala: Echinorhynchidae). I. Seasonal periodicity and new host records. Proc. Helminthol. Soc. Wash. 42, 31-34.

Muzzall, P. M., and Rabalais, F. C. (1975b). Studies on Acanthocephalus jacksoni Bullock, 1962 (Acanthocephala: Echinorhynchidae). II. An analysis of the hostparasite relationship of larval Acanthocephalus jacksoni in Lirceus lineatus (Say). Proc. Helminthol. Soc. Wash. 42, 35-38.

Muzzall, P. M., and Rabalais, F. C. (1975c). Studies on Acanthocephalus jacksoni Bullock, 1962 (Acanthocephala: Echinorhynchidae). III. The altered behavior of Lirceus lineatus (Say) infected with cystacanths of Acanthocephalus jacksoni. Proc. Helminthol. Soc. Wash. 42, 116-118. 
Oetinger, D. F. (1987). Effects of Acanthocephalus dirus (Acanthocephala) on morphometrics and reproduction of Caecidotea intermedius (Crustacea: Isopoda). Trans. Am. Microsc. Soc. 106, 240-248. doi: 10.2307/3226253

Oetinger, D. F., and Nickol, B. B. (1981). Effects of acanthocephalans on pigmentation of freshwater isopods. J. Parasitol. 67, 672-684. doi: $10.2307 / 3280441$

Oetinger, D. F., and Nickol, B. B. (1982a). Spectrophotometric characterization of integumental pigments from uninfected and Acanthocephalus dirus-infected Asellus intermedius. J. Parasitol. 68, 270-275. doi: 10.2307/3281186

Oetinger, D. F., and Nickol, B. B. (1982b). Developmental relationships between acanthocephalans and altered pigmentation in freshwater isopods. J. Parasitol. 68, 463-469. doi: 10.2307/3280959

Parker, G. A., Chubb, J. C., Roberts, G. N., Michaud, M., and Milinski, M. (2003). Optimal growth strategies of larval helminths in their intermediate hosts. J. Evol. Biol. 16, 47-54. doi: 10.1046/j.1420-9101.2003.00504.x

Perrot-Minnot, M.-J., and Cézilly, F. (2013). Investigating candidate neuromodulatory systems underlying parasitic manipulation: concepts, limitations and prospects. J. Exp. Biol. 216, 134-141. doi: 10.1242/jeb.074146

Perrot-Minnot, M.-J., Maddaleno, M., Balourdet, A., and Cézilly, F. (2012). Host manipulation revisited: no evidence for a causal link between altered photophobia and increased trophic transmission of amphipods infected with acanthocephalans. Func. Ecol. 26, 1007-1014. doi: $10.1111 / j .1365-2435.2012 .02027 . x$

Perrot-Minnot, M.-J., Sanchez-Thirion, K., and Cézilly, F. (2014). Multidimensionality in host manipulation mimicked by serotonin injection. Proc. R. Soc. B 281, 1-8. doi: 10.1098/rspb.2014.1915

Pilecka-Rapacz, M. (1986). On the development of acanthocephalans of the genus Acanthocephalus Koelreuther, 1771, with special attention to their influence on intermediate host, Asellus aquaticus L. Acta Parasitol. Pol. 30, 233-250.

Poulin, R. (1994a). The evolution of parasite manipulation of host behaviour: a theoretical analysis. Parasitology 109, S109-S118. doi: $10.1017 /$ S0031182000085127

Poulin, R. (1994b). Meta-analysis of parasite-induced behavioural changes. Anim. Behav. 48, 137-146. doi: 10.1006/anbe.1994.1220

Poulin, R. (2010). Parasite manipulation of host behavior: an update and frequently asked questions. Adv. Stud. Behav. 41, 151-186. doi: 10.1016/S0065-3454(10)41005-0

Poulin, R. (2013). Parasite manipulation of host personality and behavioural syndromes. J. Exp. Biol. 216, 18-26. doi: 10.1242/jeb.073353

Poulin, R., and Morand, S. (2000). Testes size, body size and male-male competition in acanthocephalan parasites. J. Zool. Lond. 250, 551-558. doi: 10.1111/j.1469-7998.2000.tb00796.x

Poulin, R., Brodeur, J., and Moore, J. (1994). Parasite manipulation of host behaviour. Should hosts always lose? Oikos 70, 479-484. doi: 10.2307/3545788

Poulin, R., Fredensborg, B. L., Hansen, E., and Leung, T. L. F. (2005). The true cost of host manipulation by parasites. Behav. Process. 68, 241-244. doi: 10.1016/j.beproc.2004.07.011

Read, C. P., and Phifer, K. (1959). The role of carbohydrates in the biology of cestodes. VII. Interactions between individual tapeworms of the same and different species. Exp. Parasitol. 8, 46-50. doi: 10.1016/0014-4894(59)90006-2

Réale, D., Dingemanse, N. J., Kazem, A. J. N., and Wright, J. (2010). Evolutionary and ecological approaches to the study of personality. Philos. Trans. R. Soc. B 365, 3937-3946. doi: 10.1098/rstb.2010.0222

Réale, D., Reader, S. M., Sol, M., McDougall, P. T., and Dingemanse, N. J. (2007). Integrating animal temperament within ecology and evolution. Bio. Rev. 82, 291-318. doi: 10.1111/j.1469-185X.2007.00010.x
Roberts, L. S. (2000). The crowding effect revisited. J. Parasitol. 86, 209-211. doi: 10.1645/0022-3395(2000)086[0209:TCER]2.0.CO;2

Seaman, B., and Briffa, B. (2015). Parasites and personality in periwinkles (Littorina littorea): infection status is associated with mean-level boldness but not repeatability. Behav. Process. 115, 132-134. doi: 10.1016/j.beproc.2015. 03.014

Seidenberg, A. J. (1973). Ecology of the acanthocephalan, Acanthocephalus dirus (Van Cleave, 1931), in its intermediate host, Asellus intermedius Forbes (Crustacea: Isopoda). J. Parasitol. 59, 957-962. doi: 10.2307/ 3278624

Seppälä, O., Valtonen, E. T., and Benesh, D. P. (2008). Host manipulation by parasites in a world of dead-end predators: adaptation to enhance transmission? Proc. R. Soc. B. 275, 1611-1615. doi: 10.1098/rspb.2008.0152

Sih, A., Bell, A. M., Johnson, J. C., and Ziemba, R. E. (2004). Behavioral syndromes: an integrative overview. Q. Rev. Biol. 79, 241-277. doi: 10.1086/422893

Sparkes, T. C. (1996). Effects of predation risk on population variation in adult size in a stream-dwelling isopod. Oecologia 106, 85-92. doi: 10.1007/BF003 34410

Sparkes, T. C., Weil, K. A., Renwick, D. T., and Talkington, J. A. (2006). Development-related effects of an acanthocephalan parasite on pairing success of its intermediate host. Anim. Behav. 71, 439-448. doi: 10.1016/j.anbehav.2005.06.006

Sparkes, T. C., Wright, V. M., Renwick, D. T., Weil, K. A., Talkington, J. A., and Milhalyov, M. (2004). Intra-specific host sharing in the manipulative parasite Acanthocephalus dirus: does conflict occur over host modification? Parasitology 129, 335-340. doi: 10.1017/S0031182004005645

Steinauer, M. L., and Nickol, B. B. (2003). Effect of cystacanth body size on adult success. J. Parasitol. 89, 251-254. doi: 10.1645/00223395(2003)089[0251:EOCBSO]2.0.CO;2

Thomas, F., Adamo, S., and Moore, J. (2005). Parasitic manipulation: where are we and where should we go? Behav. Process. 68, 185-199. doi: 10.1016/j.beproc.2004.06.010

Thomas, F., Brodeur, J., Maure, F., Franceschi, N., Blanchet, S., and Rigaud, T. (2011). Intraspecific variability in host manipulation by parasites. Infect. Genet. Evol. 11, 262-269. doi: 10.1016/j.meegid.2010.12.013

Thomas, F., Poulin, R., and Brodeur, J. (2010). Host manipulation by parasites: a multidimensional phenomenon. Oikos 119, 1217-1223. doi: 10.1111/j.1600-0706.2009.18077.x

Thomas, F., Rigaud, T., and Brodeur, J. (2012). "Evolutionary routes leading to host manipulation by parasites," in Host Manipulation by Parasites, eds D. P. Hughes, J. Brodeur, and F. Thomas (Oxford, UK: Oxford University Press), 16-33. doi: 10.1093/acprof:oso/9780199642236.003.0002

Wahl, G. M., and Sparkes, T. C. (2012). Egg dispersal in the acanthocephalan Acanthocephalus dirus: field data. J. Parasitol. 98, 894-896. doi: 10.1645/GE-3078.1

Conflict of Interest Statement: The authors declare that the research was conducted in the absence of any commercial or financial relationships that could be construed as a potential conflict of interest.

Copyright () 2017 Park and Sparkes. This is an open-access article distributed under the terms of the Creative Commons Attribution License (CC BY). The use, distribution or reproduction in other forums is permitted, provided the original author(s) or licensor are credited and that the original publication in this journal is cited, in accordance with accepted academic practice. No use, distribution or reproduction is permitted which does not comply with these terms. 